\title{
Explaining mesoscale variation in intertidal mussel community structure
}

\author{
Christopher W. McKindsey*, Edwin Bourget \\ GIROQ, Département de Biologie, Université Laval, Québec, Québec G1K 7P4, Canada
}

\begin{abstract}
We examined how the recruitment and structure of intertidal mussel Mytilus edulis communities and a number of variables (phytoplankton concentration, mean and maximal wave forces, water flux, abrasion by ice, along-shore distance) vary among 4 size classes of embayments (straight coastlines, and embayments with mouth openings of 100, 250 and $400 \mathrm{~m}$ ) at 12 sites over an apparently homogeneous $15.6 \mathrm{~km}$ stretch of coastline in the St. Lawrence estuary, Canada. Only species richness was influenced by embayment size such that mean richness was highest along linear coastlines. Despite larger within-site than among-site variation in community structure indices, significant correlations were found for community structure, recruitment and a number of other physical and biological variables $\left(\mathrm{r}^{2}=0.76,0.20,0.06\right.$, and 0.13 for recruitment, ShannonWeiner diversity calculated from abundance and biomass data, and richness, respectively), highlighting the importance of each of these factors to intertidal community structure. Overall, alongshore distance explained the highest proportion of variance for both recruitment (partial $\mathrm{r}^{2}=0.34$ ) and diversity calculated from abundance data (partial $r^{2}=0.11$ ). The other variables explained varying portions of the total variance of these and other indices of community structure. Possible mechanisms relating the observed patterns in community structure to the various indices measured are discussed.
\end{abstract}

KEY WORDS: Coastal heterogeneity $\cdot$ Topographic heterogeneity $\cdot$ Embayment effects $\cdot$ Mytilus edulis $\cdot$ Diversity $\cdot$ Richness $\cdot$ Recruitment $\cdot$ Exposure

Resale or republication not permitted without written consent of the publisher

\section{INTRODUCTION}

Ecological communities vary both temporally and spatially (Addicott et al. 1987, Cornell \& Lawton 1992, Tokeshi 1993). Schluter \& Ricklefs (1993) suggest that community diversity varies on 3 broad spatial scales: (1) among geographic regions-regional-scale, (2) among sites within regions-mesoscale, and (3) within sites - local scale. Most studies done at the mesoscale, the scale of interest in this study, have contrasted sites that differ markedly in at least 1 way, e.g., with respect to exposure regimes (Menge 1976, Bell \&

*Present address: Centre for Research on Ecological Impacts of Coastal Cities, Marine Ecology Laboratories, A11, University of Sydney, New South Wales 2006, Australia.

E-mail: cmckinds@bio.usyd.edu.au
Denny 1994), positions within fjords or embayments (Hansen \& Ingólfsson 1993, Rapoport 1994, Pugh \& Davenport 1997), levels of human impacts (Dye 1992, Brosnan \& Crumrine 1994), and substrate quality (McQuaid \& Branch 1984, Schoch \& Dethier 1996). Few have contrasted sites that are both separated by short (mesoscale) distances and subject to similar environmental conditions.

As mussels are commonly the dominant invertebrate species on hard surfaces in the mid- to lower intertidal range in all temperate seas (Seed 1976, Suchanek 1985, Seed \& Suchanek 1992), including the area considered in this study, an understanding of the factors that underlie their dynamics may help explain mesoscale variation in the communities of organisms associated with them. In this paper, we examine how mussel community structure in the St. Lawrence estu- 
ary, Canada, varies among adjacent sites over ca $15 \mathrm{~km}$ of coastline and relate differences to a number of factors. Each of these is outlined below.

\section{Coastal heterogeneity}

At the mesoscale, hydrodynamics and linked biological processes are influenced by, among other things, coastal heterogeneity (Okubo 1973, Wolanski \& Hamner 1988). For headlands, the effects cited are of 2 broad categories: (1) the influence of headland wake on larval concentration and subsequent recruitment (Ebert \& Russell 1988, Rankin et al. 1994), and (2) the effect of differential exposure on headlands and its influence on predation rates (Menge 1978a,b). Studies on the effects of embayments have examined how they influence recruitment (Lagadeuc 1992, Sewell \& Watson 1993, Archambault et al. 1998) and the spatial variations in community richness within them (Hansen \& Ingólfsson 1993, Rapoport 1994).

However, many studies on coastal heterogeneity have not been replicated and conclusions drawn from them, although plausible, need validation (Hurlbert 1984, Underwood \& Petraitis 1993). Replicated sites displaying the factor of interest must be studied and compared to similar sites without that factor in order to attribute between-site differences to that effect. Further, with the exception of Archambault \& Bourget (1996, 1998, 1999) and Blanchard \& Bourget (1999), the influence of the scale of mesoscale topographic features on community structure has not been examined.

\section{Climatic severity}

The diversity of a community may be a function of the disturbance regime it experiences (Connell 1978, Sousa 1979, Dial \& Roughgarden 1998). In marine intertidal environments, one of the most commonly cited indices of physical disturbance is wave action (Jones \& Demetropoulos 1968, Bustamante \& Branch 1996). Embayments may limit wave action on their shores because of a 'wave shadow' created by the directional aspect of the waves or because small embayments tend to be shallow and waves that do reach the intertidal zone may be smaller than on the open coast or in large embayments. Subarctic regions such as the one examined in this study are scoured by ice each year (Mathieson et al. 1991), which may be a dominant and spatially variable force shaping intertidal communities in these regions. For instance, mussel communities in the St. Lawrence estuary are limited to crevices, the base of boulders and other sub- strate irregularities because of this annual event (Bergeron \& Bourget 1986). Embayment size may influence abrasion by ice by altering its movement.

\section{Energy supply}

The size of an embayment modifies the retention time of the water it contains (Okubo 1973, Sanford et al. 1992) and of the particles suspended within this water, including phytoplankton (Archambault et al. 1999), a major source of food for filter feeders such as mussels (Newell et al. 1989, Seed \& Suchanek 1992). As the energy supplied to a system may have numerous effects, ultimately influencing specific diversity and community structure (Pianka 1988, Wright et al. 1993, Menge et al. 1997a,b), differences in the quantity of phytoplankton supplied to benthic communities dominated by filter feeders may have a significant impact on them. This is the basis of the nutrient/productivity hypothesis (Menge et al. 1995). It states that differences in benthic communities dominated by suspension-feeding invertebrates, such as mussels, result from differences in top-down factors (interaction strength) that are attributable to differences in nearshore primary productivity and other linked bottom-up factors. Thus, differences in the standing stock of phytoplankton between sites, due to either differences in primary productivity (Dahlhoff \& Menge 1996, Archambault et al. 1999) or entrapment (Roff et al. 1979), may lead to differences in community structure among embayments of different sizes or sites.

\section{Recruitment}

The structure and functioning of communities are also dependent on the rate of recruitment of their component species (Osman 1977, Booth \& Brosnan 1995, Caley et al. 1996, Robles 1997), which may vary greatly among sites (Underwood \& Denley 1984, Caffey 1985). Thus, communities may differ among sites because of variation in recruitment due to embayment size, geographic location, and/or any of the other previously discussed variables.

The goals of this study were to test whether intertidal mussel communities vary over the mesoscale and whether this is a function of the size of embayments $\leq 400 \mathrm{~m}$. We then tested whether (1) exposure, (2) energy supply (phytoplankton standing stock), and (3) recruitment vary among embayments of different sizes and/or among sites and if such variation may explain observed differences in community structure. We also examined the correlation between recruitment strength and the other variables measured. 


\section{METHODS}

Study site. Sites were located along a $15.6 \mathrm{~km}$ stretch of coastline on the south shore of the St. Lawrence estuary centred around Grosses Roches, Québec, Canada $\left(48^{\circ} 56^{\prime} \mathrm{N}, 67^{\circ} 10^{\prime} \mathrm{W}\right)$. This area was selected because of a high concentration of embayments over a relatively short coastline, thereby reducing among-site variability due to larger-scale variation in community structure. Tides are diurnal with mean and maximal fluctuations of approximately 2.6 and $4.1 \mathrm{~m}$, respectively. Typical summer surface salinity and temperature are $27 \mathrm{ppt}$ and $14^{\circ} \mathrm{C}$ (Fradette \& Bourget 1980).

Embayments. Smooth coastlines $(\mathrm{n}=5)$ and embayments with mouth openings of $100(\mathrm{n}=4), 250(\mathrm{n}=3)$ and $400 \mathrm{~m}(\mathrm{n}=3)$ and with depths at least $1 / 3$ their breadth were selected for possible study. From these, 3 embayments of each size and 3 smooth coastlines (hereafter considered as embayments with mouth openings of $0 \mathrm{~km}$ ) were selected (randomly, when possible) for intensive study. All sites selected were pocket beaches of well-rounded boulders 0.3 to $1.0 \mathrm{~m}$ in diameter overlaying an unconsolidated substrate composed of sand and larger particles. None had any evident source of freshwater run-off.

Boulders and sampling. Typical boulder mussel communities appear mostly limited to a well-defined collar around the middle of boulders. This is presumably due to the annual abrasion by ice and intense predation by the whelk Nucella lapillus defining the upper and lower limits of the communities, respectively. Above this collar, a variety of ephemeral algae may be present with the occasional 'island' of small mussels found, usually associated with some irregularity in the boulder and presumably recently recruited. Other than $N$. lapillus, littorinids, and a few hydrozoans, few animals or algae occur below the lower limit.

The near total absence of organisms in positions other than those protected from the annual abrasion by ice (Bergeron \& Bourget 1986) makes random sampling impractical in this study area. Six boulders at roughly the same intertidal height (approx. 1.0 to $1.5 \mathrm{~m}$ above chart datum) and between 0.35 and $0.80 \mathrm{~m}$ in diameter were randomly selected for sampling in the base (i.e., the most inland portion) of each embayment. From the north position on each boulder (facing the estuary), a $10 \times 10 \mathrm{~cm}$ sample was taken from the upper limit of mussels. All animals and algae within the quadrats sampled were collected. Each sample was placed in a plastic bag and frozen until analysis in the laboratory. In the lab, samples were passed through a series of 5 screens $(500 \mu \mathrm{m}, 1,2,4$ and $8 \mathrm{~mm}$ mesh). The animals and algae collected on each screen were identified to the lowest taxonomic level possible, counted, blotted dry and their weights recorded.
Climatic severity. Wave exposure was evaluated in 2 separate ways. First, a measure of the relative flux of water was estimated as the erosion of plaster cylinders (Muus 1968). Cylinders $(9 \times 2.6 \pm 0.1 \mathrm{~cm}$ with a $0.5 \mathrm{~cm}$ hole passing through the length and capped at both ends by a layer of fibreglass resin) were secured vertically onto the top of rocks using stainless steel bolts screwed into plastic anchors and held in place by wing nuts. Erosion was evaluated as the mass lost (cylinders air-dried to constant mass) following $24 \mathrm{~h}$ periods (2 tidal cycles) in the field. Erosion of plaster was measured from the same 5 randomly selected rocks in each embayment on 6 separate dates in July-August 1996 (once a week for 6 consecutive weeks on randomly chosen days within weeks).

Second, wave force in embayments was estimated using dynamometers (Bell \& Denny 1994). This approach may provide a more realistic index of exposure than water flux, as it is generally the maximal rather than average drag created by water velocities that determines whether an organism will be broken or dislodged (Denny \& Gaines 1990, Denny 1995). Three of these devices were deployed in each embayment and replaced at regular intervals for routine maintenance. Except for a $1 \mathrm{wk}$ period, measurements were taken every other day from 7 July to 23 August 1996.

The intensity of ice abrasion was measured as the over-winter 'survival' of 50 small $(\sim 1 \mathrm{~cm}$ high) cement cones that were secured to the tops of 50 haphazardly chosen boulders in the area where samples were taken in each embayment in September 1995. The cones were made of Quick Plug Hydraulic Cement (Bondex International Ltd) using ice-cube trays as forms and painted with yellow enamel floor paint (Crown Diamond) to facilitate their recovery in the spring. After drying the surface of boulders used thoroughly with a blowtorch, cones were glued in place with fibreglass resin at least $3 \mathrm{~h}$ before the tide returned to that level. A cursory examination $2 \mathrm{wk}$ after cones were installed confirmed their presence before winter. 'Survivorship' of the cones was determined in May 1996.

Energy supply. Phytoplankton abundance was estimated as chlorophyll a ( $\mathrm{chl}$ a) concentrations. Two zones were established within each sample site. The first (inshore) was located in the base of the embayments or along the straight coasts at the $2 \mathrm{~m}$ isobath, directly above the intertidal benthic communities sampled. For straight coasts, the offshore zone was located at a distance from the shore approximately twice that of the first zone. For embayments, the offshore zone was located at a distance outside of the embayments equal to that between the shore and the inshore zone. The offshore zones were sampled in an attempt to partial out larger-scale between-site variance that is not due to embayment size effects. The sampling schedule 
called for each of the 12 sites to be sampled over periods of 3 d in July, August and September. However, storms prevented this and the actual sampling dates were 31 July, 2-3, 23, 24 and 30 August, and 25-26 September 1995. All samples were taken \pm 45 min of high tide. Sampling was done by taking triplicate samples (5 1 Niskin bottles) at depths of $1.75 \mathrm{~m}$ at each zone. Water samples were transferred to the laboratory in insulated Coleman bottles and processed within $4 \mathrm{~h}$ of collection. In the laboratory, $200 \mathrm{ml}$ aliquots were filtered onto $25 \mathrm{~mm}$ GF/F75 glass fibre filters (AMD Manufacturing), the filters wrapped in aluminium foil and frozen for up to 4 mo before being analyzed for chl a concentration using the acetone-extraction method and a Turner Designs (model 10) fluorometer (see Fréchette \& Bourget 1985).

Recruitment. Only the recruitment of the dominant species, the mussel Mytilus edulis, was determined. To avoid variance due to differential settlement on natural substrates that may obscure among-site differences, recruitment was estimated using standardized collectors. The collectors were multifilament nylon bags $(25 \times 30 \mathrm{~cm})$ with a $3 \mathrm{~mm}$ mesh filled with a standardized quantity $(78 \mathrm{~g})$ of monofilament $(1 \mathrm{~cm}$ mesh of $0.5 \mathrm{~mm}$ diameter). Collectors were affixed to the top of 5 rocks in each study site by cords attached to each corner of the collectors, which were tied to screws fixed in the rock by plastic anchors. The rocks selected were the same as those used to determine water flux (see 'Climatic severity' above) and cylinders and collectors were 15 to $20 \mathrm{~cm}$ apart. The collectors were deployed on 10-11 June and collected 6 to 9 September 1996. Each collector was placed in a separate plastic bag for transport to the lab. The collectors were then cleaned in a $10 \% \mathrm{NaOCl}$ solution (Pouliot et al. 1995) and all organisms from the wash and rinse waters retained by a $150 \mu \mathrm{m}$ screen preserved in $70 \%$ ethanol for subsequent analysis. Most samples were fractionated using a Motoda sampler and the number of mussels $>500 \mu \mathrm{m}$ determined using a dissecting microscope as an estimate of recruitment.

Statistical analysis. Three indices of community structure were calculated and analyzed: species richness $(S)$ and Shannon-Wiener diversity $\left(H^{\prime}\right)$, the latter calculated in terms of both abundance $\left(H^{\prime}{ }_{\text {no }}\right)$ and biomass $\left(H^{\prime}{ }^{\prime}\right)$, as suggested by Tokeshi (1993). As many indices of community structure are known to be influenced by the size of the organisms examined (Reish 1959, Bachelet 1990), we considered each size class of organisms separately for the above-mentioned indices. Community and wave force data were analyzed by repeated-measures nested ANOVA with embayments nested within embayment sizes. Depending on the analysis, either organism size or sample date were considered as the repeated factors. The data for the water flux study were analyzed using a nested ANCOVA with height above chart datum as the covariate. The phytoplankton data were examined as a crossed nested design. The statistical test used to analyze the recruitment data is outlined in the 'Results'. A series of stepwise regressions was used to examine the importance of the various parameters measured to $H^{\prime}{ }_{\text {no, }} H^{\prime}{ }_{\text {wt }}$ and $S$ calculated from all size classes of organisms combined and for the recruitment of Mytilus edulis.

Community structure among embayment sizes and sites was also examined using analysis of similarities (ANOSIM) (Clarke 1993) based on Bray-Curtis similarities calculated from fourth-root transformed abundance data (Clarke \& Green 1988) and the trends highlighted by the construction of multi-dimensional scaling (MDS) plots. Similarity matrices were also used to relate community structure indices to the other variables calculated by the BIOENV procedure, as outlined by Clarke \& Ainsworth (1993).

Data sets for $H^{\prime}{ }_{\text {no, }} H^{\prime}{ }_{\text {wt }}$, and $S$ were all square-root transformed and those for the wave-force, phytoplankton, and recruitment studies were log-transformed
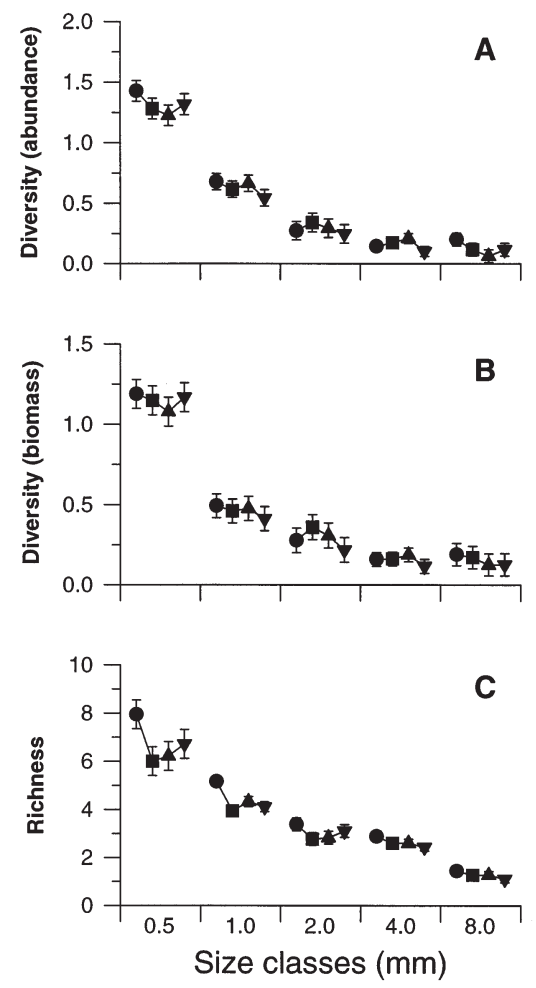

Fig. 1. Mean $( \pm \mathrm{SE})$ Shannon-Weiner diversity calculated in terms of (A) animal counts and (B) biomass, and (C) richness of the organisms within mussel communities as a function of organism size from 4 sizes of embayments. Circles, squares, triangles and upside-down triangles represent embayments of 0 (straight coastlines), 100, 250 and $400 \mathrm{~m}$, respectively. Note that the data presented have been back-translated from the transformed data used in the analyses 
prior to analysis to meet the assumptions of homoscedasticity and normality (confirmed by evaluation of residual plots; Tabachnick \& Fidell 1989). ANCOVA models were first run to test the assumption of homogeneity of regressions and, when not significant, the interaction factor was dropped from all subsequent models (Tabachnick \& Fidell 1989). Post-hoc testing (LSMeans tests; SAS Institute 1996) for differences between means in ANOVAs was performed by modifying the critical $\alpha$ employed (0.05) by sequential Bonferroni adjustments (Rice 1989). All parametric analyses were carried out using the SAS system for Windows (SAS Institute 1996). Nonparametric statistics were performed using PRIMER (Carr 1996).

\section{RESULTS}

\section{Embayment size and community structure}

The $8 \mathrm{~mm}$ size class was dropped from all analyses of community structure (although the results are displayed in the figures for comparison) because very few organisms except mussels were of this size. The magnitude in variation observed at the m-scale (among samples within sites) was almost an order of magnitude greater than that at the km-scale (among sites within sizes) for all indices of diversity measured (Table 1). Although the size of the organisms included in the analyses greatly influenced both $H^{\prime}$ no and $H^{\prime}{ }_{\text {wt }}$ (Table 1), neither of these indices varied among embayment sizes (Table 1, Fig. 1). Embayment size did, however, influence species richness (Table 1, Fig. 1). Bonferroni-adjusted post-hoc examination of the 4 size classes of organisms examined showed that only organisms retained by the $1 \mathrm{~mm}$ sieve differed among embayment sizes (data not shown). Although further adjustment of the probability level needed to conclude significant differences failed to determine which size classes of embayments differed in terms of richness, if an ANOVA is significant then at least the 2 most extreme groups must be different (Underwood 1997). Fig. 1 shows that the richness observed along the linear coastlines is consistently higher than that observed within the embayments for all size classes of organisms. Thus, linear coastlines supported a higher mean

Table 1. Results of repeated measures nested ANOVA examining the influence of embayment size (Size, fixed factor; Bay, random factor) on the diversity and richness $(S)$ of benthic intertidal communities calculated for 4 size classes of organisms (Body, repeated factor). Diversity was calculated in terms of both abundance $\left(H^{\prime}{ }_{\text {no }}\right)$ and biomass $\left(H^{\prime}{ }_{\text {wt }}\right)$. Between and within subject effects are presented. All data were square-root transformed to meet the assumptions of the statistical tests. VC: variance components calculated for each variable in the models

\begin{tabular}{|c|c|c|c|c|c|}
\hline Source of variation & MS & df & $F$ & $\mathrm{p}$ & $\mathrm{VC}$ \\
\hline \multicolumn{6}{|l|}{$H_{\text {no }}^{\prime}$} \\
\hline Size & 0.039 & 3 & 0.45 & 0.722 & 0.000 \\
\hline Bay (Size) & 0.086 & 8 & 1.79 & 0.097 & 0.014 \\
\hline Error & 0.049 & 60 & & & 0.037 \\
\hline Body & 8.641 & 3 & 418.35 & $<<0.001$ & 0.786 \\
\hline Body $\times$ Size & 0.026 & 9 & 0.61 & 0.779 & 0.000 \\
\hline Body $\times$ Bay (Size) & 0.044 & 24 & 2.11 & 0.003 & 0.025 \\
\hline Error & 0.021 & 180 & & & 0.138 \\
\hline \multicolumn{6}{|l|}{$H_{\text {wt }}^{\prime}$} \\
\hline Size & 0.033 & 3 & 0.35 & 0.790 & 0.000 \\
\hline Bay (Size) & 0.095 & 8 & 1.75 & 0.104 & 0.019 \\
\hline Error & 0.054 & 60 & & & 0.049 \\
\hline Body & 6.876 & 3 & 311.09 & $<<0.001$ & 0.725 \\
\hline Body $\times$ Size & 0.016 & 9 & 0.30 & 0.969 & 0.000 \\
\hline Body $\times$ Bay (Size) & 0.053 & 24 & 2.42 & $<0.001$ & 0.040 \\
\hline Error & 0.022 & 180 & & & 0.168 \\
\hline \multicolumn{6}{|l|}{$S$} \\
\hline Size & 0.654 & 3 & 4.78 & 0.034 & 0.014 \\
\hline Bay (Size) & 0.137 & 8 & 0.63 & 0.751 & 0.007 \\
\hline Error & 0.218 & 60 & & & 0.095 \\
\hline Body & 13.388 & 3 & 176.63 & $<<0.001$ & 0.619 \\
\hline Body $\times$ Size & 0.080 & 9 & 0.84 & 0.590 & 0.000 \\
\hline Body $\times$ Bay (Size) & 0.095 & 24 & 1.25 & 0.202 & 0.011 \\
\hline Error & 0.076 & 180 & & & 0.255 \\
\hline
\end{tabular}


Table 2. Results of repeated measures nested ANCOVA examining the influence of embayment size (Size, fixed factor; Bay, random factor) on the dissolution of plaster cylinders on 5 sampling dates (Date, repeated factor) and at different intertidal heights (High, continuous covariate). Because of non-sphericity, probabilities given are those calculated using an Huynh-Feldt adjustment

\begin{tabular}{|lrrrr|}
\hline Source of variation & MS & df & $F$ & $p$ \\
\hline Size & 57.329 & 3 & 1.95 & 0.201 \\
Bay (Size) & 29.471 & 8 & 5.18 & $<0.001$ \\
High & 39.183 & 1 & 6.88 & 0.012 \\
Error & 5.694 & 47 & & \\
Date & 30.726 & 4 & 18.72 & $<<0.001$ \\
Date $\times$ Size & 5.021 & 12 & 0.76 & 0.687 \\
Date $\times$ Bay (Size) & 4.679 & 32 & 3.74 & $<0.001$ \\
Date $\times$ High & 13.373 & 4 & 7.96 & $<0.001$ \\
Error & 1.885 & 188 & & \\
\hline
\end{tabular}

richness than was observed within the embayments adjacent to these sites.

No clear patterns for embayment size are indicated in the MDS plot, which provides only a fair representation of the information contained within the similarity matrix (Fig. 2, stress $=0.21$ ). No significant differences in community structure among embayment sizes were detected by ANOSIM ( $R=-0.090, p=0.738)$ but sites did differ within embayment sizes $(R=0.250, p<0.001)$. In contrast to the results of parametric tests, the nonparametric MDS plot (Fig. 2) shows that community structure was more variable at the $\mathrm{km}$ - than at the m-scale, as samples from within sites typically group together in various parts of the plot. Thus, the relative importance of different spatial scales to variation in community structure differed between parametric and nonparametric analyses. Variation at the m-scale was greater than that at the $\mathrm{km}$-scale using parametric tests, whereas the converse was true for the nonparametric tests.

\section{Climatic severity}

Water flux was greatest on the last sampling date and least the week before that (Table 2, Fig. 3). Although Fig. 3 shows that the water flux along straight coastlines and within the $400 \mathrm{~m}$ embayments was higher than in the 100 and $250 \mathrm{~m}$ embayments on all sampling dates, these differences were not significant (Table 2). The influence of the covariate, intertidal height, differed among sampling dates (Table 2). These differences are reflected in the differences in the univariate slopes calculated within the repeated measures model (Table 3). Slopes varied significantly only between the last sampling date and sampling

Table 3. Univariate slopes and probabilities of the regressions relating plaster dissolution to intertidal height calculated within a repeated measures nested ANCOVA model examining the effect of embayment size on the flux of water on 5 sampling dates

\begin{tabular}{|crr|}
\hline Sampling date & Slope & \multicolumn{1}{c|}{$\mathrm{p}$} \\
\hline 1 & -1.403 & 0.365 \\
2 & 2.873 & 0.377 \\
3 & -5.382 & 0.004 \\
4 & -1.551 & 0.168 \\
5 & -10.484 & $<0.001$ \\
\hline
\end{tabular}

Fig. 3. Mean $( \pm \mathrm{SE})$ dissolution of plaster within 4 size classes of embayments on 5 sampling dates. Equivalent letters (sequential Bonferroni tests) indicate sampling dates that do not differ significantly. Circles, squares, triangles and upsidedown triangles represent embayments of 0, 100, 250 and $400 \mathrm{~m}$, respectively 


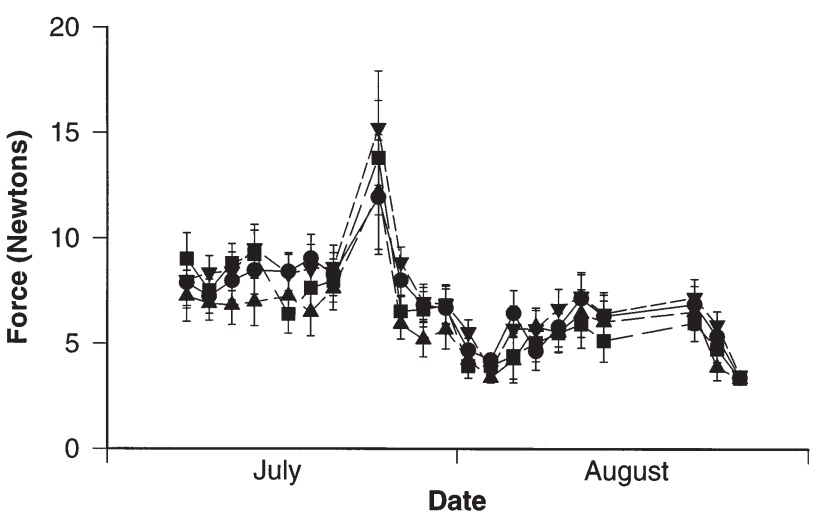

Fig. 4. Mean wave forces $( \pm \mathrm{SE})$ recorded within embayments of different sizes through the summer of 1996. Circles, squares, triangles and upside-down triangles represent embayments of $0,100,250$ and $400 \mathrm{~m}$, respectively. Note that the data presented have been back-translated from the transformed data used in the analyses

dates 1,2 , and 4 . In contrast to the high plaster loss and strong intertidal height effects observed on the last sampling date, plaster loss was not great on the third sampling date, yet the slopes calculated were nonetheless significant. This may be explained by small tides coupled with moderate winds on that date.

On one of the planned sampling dates in the waveforce study, only about half of the dynamometers were examined because of unsafe conditions (bad storm). The readings taken on that date were used in lieu of those taken $2 \mathrm{~d}$ later and the first of these 2 sampling dates dropped from the analyses. Following the storm, 3 of the dynamometers recorded forces equal to their maxima. As many other dynamometers approached their maxima during this storm, we believe these readings represent realistic forces experienced by the sites at this time and we used the upper detection limits of the devices as data, although these values are probably lower than those forces actually present during the storm. On 7 other occasions, a single dynamometer

Table 4. Results of repeated measures nested ANOVA examining the influence of embayment size (Size, fixed factor; Bay, random factor) on the wave force on 21 sampling dates (Date, repeated factor). Because of non-sphericity, probabilities given are those calculated using Huynh-Feldt adjustments

\begin{tabular}{|lrrrr|}
\hline Source of variation & \multicolumn{1}{c}{ MS } & df & $F$ & \multicolumn{1}{c|}{$\mathrm{p}$} \\
\hline Size & 1.559 & 3 & 0.66 & 0.597 \\
Bay (Size) & 2.346 & 8 & 6.55 & $<0.001$ \\
Error & 0.358 & 24 & & \\
Date & 3.282 & 20 & 107.05 & $<<0.001$ \\
Date $\times$ Size & 3.981 & 60 & 0.76 & 0.889 \\
Date $\times$ Bay (Size) & 13.991 & 160 & 2.85 & $<0.001$ \\
Error & 14.719 & 480 & & \\
\hline
\end{tabular}

had obviously been either tampered with or fouled such that the maximal force for the apparatus was reached. In these cases, the mean of the other 2 force readings taken on the same day in the same embayment were substituted in their place.

There are obvious temporal trends evident in the wave force data (Fig. 4, Table 4), which was greater in July than in August. The maximal wave force recorded from any given rock within all embayments was that recorded during the storm of 19 to 21 July, as evident by a peak in Fig. 4. However, the size of embayments did not influence the mean maximal wave force recorded within the different sites (Fig. 4, Table 4).

Evidence (fibreglass resin on rocks) of between 27 and 46 of the 50 cones installed in each embayment in the fall of 1995 was found in the spring of 1996. No cement cones were found intact on the rocks. These results suggest simply that abrasion by ice occurs at each site but our data do not allow a test of whether the intensity of abrasion differs among sites.

\section{Energy supply}

Chl a concentration varied with respect to the interaction between sampling date and the zone sampled (Table 5). Concentrations of chl a were always lower within embayments than in zones immediately outside of them, but this difference was only significant for the September sampling (Fig. 5). Chl a concentrations within the inshore zones did not vary with sampling date (Fig. 5). Within the offshore zones, concentration of chl a was significantly higher in September than in July, and that in August did not differ from either July or September (Fig. 5).

\section{Recruitment}

An initial examination of the data detected an outlier almost an order of magnitude smaller than the next smallest data point for that embayment. This data point was replaced by a value one less than that of the nextsmallest data point for that embayment (Sokal \& Rohlf 1995). Stepwise regression was used to determine which of 6 factors (linear distance [km] along the coastline of the sampling sites where ' 0 ' is the distance of the embayment the furthest to the west, the intertidal height and mean water flux associated with each collector, the mean concentration of chl $a$ in inshore zones and the mean [of the 21 sam- 
Table 5. Nested ANOVA table showing the influence of embayment size (Size) and sampling date (Date) on the concentration of chl a within 2 zones (Zone) within each embayment (Bay)

\begin{tabular}{|lrrrr|}
\hline Source of variation & df & MS & \multicolumn{1}{c|}{$F$} & $\mathrm{p}$ \\
\hline Size & 3 & 0.474 & 0.605 & 0.630 \\
Bay $($ Size) & 8 & 0.784 & 1.059 & 0.436 \\
Zone $\times$ Size & 1 & 39.716 & 27.712 & 0.001 \\
Zone $\times$ Say $($ Size) & 3 & 1.199 & 0.836 & 0.511 \\
Zone $\times$ Bat & 8 & 1.433 & 1.935 & 0.124 \\
Date & 2 & 2.772 & 2.073 & 0.158 \\
Date $\times$ Size & 6 & 0.703 & 0.526 & 0.780 \\
Date $\times$ Bay $($ Size $)$ & 16 & 1.337 & 1.806 & 0.124 \\
Date $\times$ Zone & 2 & 5.360 & 7.237 & 0.006 \\
Date $\times$ Zone $\times$ Size & 6 & 0.851 & 1.149 & 0.380 \\
Date $\times$ Zone $\times$ Bay $($ Size $)$ & 16 & 1.337 & 15.137 & $<0.001$ \\
Error & 144 & 0.088 & & \\
& & & & \\
\hline
\end{tabular}

Table 6. Significant factors as determined from stepwise regression of water flux, linear distance along the coastline of sampling sites (Distance), intertidal height (High), the mean concentration of chl a from inshore zones (Phytoplankton), and the mean (MEANwave) and maximal (MAXwave) wave forces recorded from the 12 sites studied on the recruitment of Mytilus edulis to artificial collectors. Data for $M$. edulis were $\log (x)$ transformed to meet the assumptions of the statistical model. Adjusted $\mathrm{r}^{2}$ of final model $=0.759, \mathrm{df}=59$. Variables are presented in the order in which they entered into the statistical model

\begin{tabular}{|lccrr|}
\hline Variable & Parameter estimate & Partial $\mathrm{r}^{2}$ & \multicolumn{1}{c|}{$F$} & $\mathrm{p}$ \\
\hline Intercept & 3.434 & - & 152.13 & $<0.001$ \\
Distance & -0.021 & 0.338 & 9.79 & 0.003 \\
High & -0.602 & 0.244 & 21.26 & $<0.001$ \\
Phytoplankton & 1.582 & 0.074 & 29.77 & $<0.001$ \\
MAXwave & 0.040 & 0.090 & 30.22 & $<0.001$ \\
MEANwave & -0.078 & 0.033 & 8.18 & 0.006 \\
\hline
\end{tabular}

recruitment. Water flux was significant in neither the multiple regression model (Table 6) nor in a simple linear model (Fig. 6).

As some of the factors used in the above regression model are fixed within a given embayment, an ANCOVA model using them as covariables may not be used to test whether recruitment varies with embayment size. To get around this constraint, we used the residuals from the regression model outlined above as the dependent variable in a nested ANOVA model to test the influence of embayment size on recruitment. Recruitment of mussels did not vary with embayment size (Table 7, Fig. 7).

\section{Linking community structure to other factors}

Although the community structure indices did not vary among embayments of different sizes, the significant nested factors indicated significant variation among sites. We tested the contribution of 6 factors that could potentially influence community structure (differences in $H_{\text {no, }}^{\prime} H^{\prime}{ }_{\text {wt, }}$ and $S$ and the nonparametric multivariate community structure information con- pling dates] and greatest [single date] maximal wave forces recorded within the embayments) best explain the recruitment of Mytilus edulis. Water flux was calculated as the mean of the 5 ANCOVA-standardized (with respect to intertidal height) mean water fluxes calculated for each sampling date. All other independent variables used were based on raw data. Recruitment was a function of the concentration of chl $a$ and all physical parameters measured, except water flux (Table 6). The linear distance along the coastline and intertidal height of the collectors explained considerable (34 and $24 \%$ of the total variance, respectively) amounts of the total variation in recruitment, with the other factors explaining lesser but nonetheless significant portions of the remaining variance. Recruitment was positively correlated to chl a concentration and the greatest wave force recorded at a site and negatively to the mean wave forces recorded at the sites (Table 6). This is seen in the simple regressions of recruitment with each of the 6 factors (Fig. 6a-f). Together, these factors explained nearly $76 \%$ of the total variation in

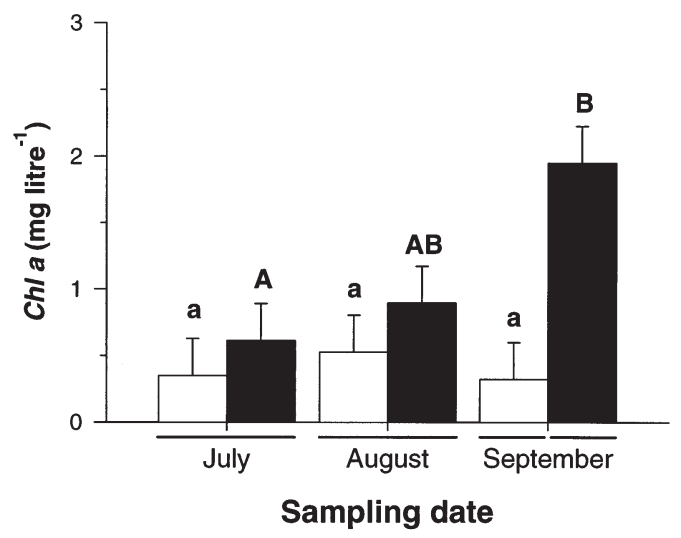

Fig. 5. Mean $( \pm \mathrm{SE})$ concentration of chl $a$ at 2 zones (inshore, empty bars; offshore, filled bars) for embayments on 3 sampling dates. For a given sampling date, non-continuous bars indicate means not significantly different between zones. For a given zone, means not differing significantly between sampling dates are indicated by equivalent small (within embayments) or capital (outside of embayments) letters. Note that the data presented have been back-translated from the transformed data used in the analyses 

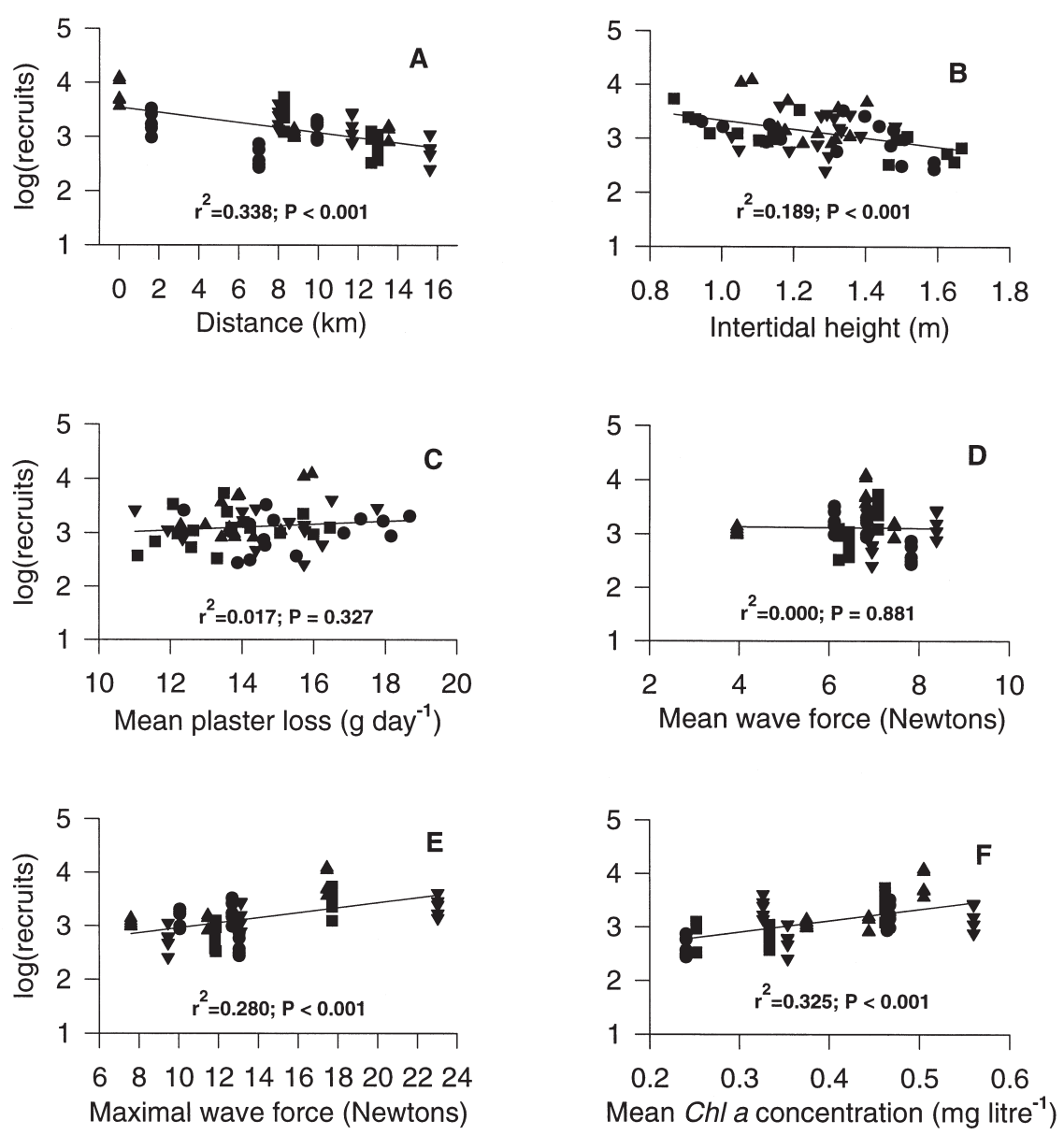

Fig. 6. Simple linear regressions of the number of Mytilus edulis recruiting to artificial collectors as a function of (A) the linear distance of the collection sites along the shore line, (B) the height of the collectors above chart datum, $(\mathrm{C})$ the mean dissolution $(\mathrm{n}=$ 5) of plaster cylinders adjacent to the collectors, (D) the mean and (E) maximal wave forces recorded, and (F) the mean concentration of chl a recorded from the inshore zones of the different sites. Circles, squares, triangles and upside-down triangles represent embayments of $0,100,250$ and $400 \mathrm{~m}$, respectively

tained within the similarity matrix). With the exception of intertidal height, these factors were the same as those used for the stepwise regression of recruitment as well as recruitment itself. The measure of recruitment used was the ANCOVA-standardized (to intertidal

Table 7. Nested ANOVA table showing the influence of embayment size (<500 m, Size) on the recruitment of Mytilus edulis to artificial collectors. The data used are the residuals from Table 6 in order to remove the effect of intertidal height and the along-shore linear distance of the sampling sites (Bay) from the statistical model

\begin{tabular}{|lcrcc|}
\hline Source of variation & MS & df & $F$ & $p$ \\
\hline Size & 0.022 & 3 & 0.562 & 0.655 \\
Bay (Size) & 0.040 & 8 & 1.424 & 0.211 \\
Error & 0.028 & 48 & & \\
\hline
\end{tabular}

height) mean recruitment for each embayment. This measure was calculated from $\log (x)$-transformed data (see above). As richness also varies with embayment size (see above), embayment size was also included in the analysis through the construction of a series $(n=3)$ of dummy variables (Hardy 1993) that were forced into the regression model before the stepping procedure started.

Three (along-shore distance, mean and maximal wave forces), 1 (water flux), and 1 (recruitment, in addition to embayment size) factors explained significant amounts of the total variance in $H^{\prime}{ }_{\text {no }} H^{\prime}{ }_{\text {wt }}$, and $S$, respectively (Table 8). All the significant measures of exposure indicate that, over the range studied, both $H^{\prime}{ }_{\text {no }}$ and $H^{\prime}{ }_{\text {wt }}$ increase with increasing exposure. That the relationship between along-shore distance and $H^{\prime}$ no was significant and positive shows that the diversity of communities increased in downstream loca- 


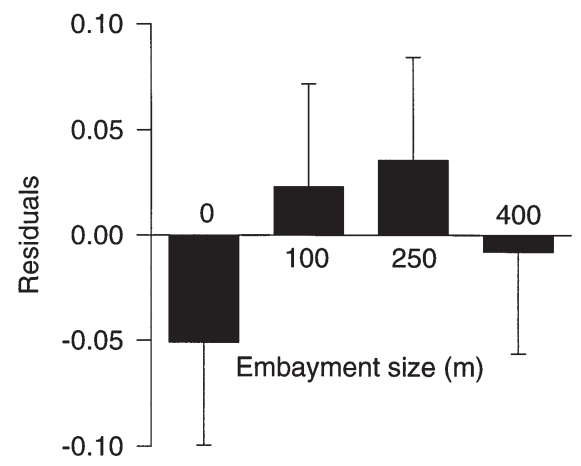

Fig. 7. Effect of embayment size on the recruitment of Mytilus edulis to artificial collectors. The dependent variables are the residuals from the regression model (see Table 6) explaining differences due to height of the collectors above chart datum and the linear distance along the coastline

tions. Increasing recruitment of Mytilus edulis was correlated with increasing species richness. However, although statistically significant, these effects explain very little of the total variance in any of the parameters measured (see Table 8). Similarly, the nonparametric multivariate BIOENV test showed that among all possible combinations of the 6 independent variables, along-shore distance by itself had the highest correlation to the information contained in the similarity matrix for all the samples collected. However, as with the parametric statistics, only a fraction of the total variation was explained (Spearman rank correlation: $\mathrm{r}=0.10, \mathrm{p}>0.25$ ).

\section{DISCUSSION}

To date, most studies that compare intertidal community structure between sites have attempted to correlate variability to gross differences in a number of physical or biological variables. Such variables include 'exposure' (e.g., Tsuchiya 1979, Hansen \& Ingólfsson 1993, Bustamante \& Branch 1996), recruitment (Gaines \& Roughgarden 1985, Bingham 1992, Connolly \& Roughgarden 1998), and phytoplankton abundance (Menge et al. 1995, 1997b). However, a simple classification of sites as either 'exposed' or 'protected' is ambiguous and attempts at modeling this effect are impossible. The term 'exposure' itself is troublesome as it may be defined in a number of different ways (Bell \& Denny 1994). Furthermore, other variables may be correlated with exposure and a separation of the importance of each of these requires some quantification of 'exposure' and of these other variables. For example, headlands are not only more exposed than adjacent sites, but recruitment to them may also be much higher (Ebert \& Russell 1988, Connolly \& Roughgarden 1998). Determining which factors are important is not easy. Similarly, although recent attempts to relate differences between local phytoplankton abundance (Menge et al. 1995, 1997b) and this and other measurements (Menge et al. 1997a, Leonard et al. 1998) are consistent with an hypothesis of bottom-up factors controlling community structure, the studied sites represent widely divergent points along a continuum. Further studies examining a range of different factors must be carried out to determine

Table 8. Factors explaining significant amounts of variation of the dependent variables from stepwise regressions of 6 independent variables on the diversity $\left(H^{\prime}{ }_{\text {no }}\right.$ and $\left.H^{\prime}{ }_{\text {wt }}\right)$ and richness $(S)$ of intertidal communities. Independent variables included the linear distance along the coastline of the sampling sites (Distance), the mean water flux (Flux), concentration of phytoplankton and recruitment of mussels within the embayments (Recruitment), and the mean (MEANwave) and maximal (MAXwave) wave forces recorded within embayments. Embayment size was also included in the model as a series of dummy variables (Dum1, Dum2, Dum3). Adjusted $r^{2}$ of the final models are $0.198,0.056$, and 0.130 for $H_{\text {nor }}^{\prime} H^{\prime}{ }_{w t}$ and $S$, respectively. df $=59$. See text for details

\begin{tabular}{|c|c|c|c|c|}
\hline Variable & Parameter estimate & Partial $\mathrm{r}^{2}$ & $F$ & $\mathrm{p}$ \\
\hline \multicolumn{5}{|l|}{$\boldsymbol{H}_{\text {no }}^{\prime}$} \\
\hline Intercept & 0.532 & - & 7.06 & 0.010 \\
\hline Distance & -0.031 & 0.105 & 16.40 & $<0.001$ \\
\hline MEANwave & 0.101 & 0.069 & 10.41 & 0.002 \\
\hline MAXwave & 0.927 & 0.058 & 5.09 & 0.027 \\
\hline \multicolumn{5}{|l|}{$H^{\prime}{ }_{\text {wt }}$} \\
\hline Intercept & 0.941 & - & 9.65 & 0.003 \\
\hline Flux & 0.048 & 0.069 & 5.20 & 0.026 \\
\hline \multicolumn{5}{|l|}{$S$} \\
\hline Intercept & 4.579 & - & 2.77 & 0.101 \\
\hline Duml & -1.924 & 0.087 & 7.13 & 0.010 \\
\hline Dum2 & -2.283 & 0.119 & 9.71 & 0.003 \\
\hline Dum3 & -1.597 & 0.060 & 4.92 & 0.030 \\
\hline Recruitment & 1.795 & 0.051 & 4.19 & 0.045 \\
\hline
\end{tabular}


how they act and interact to influence community structure.

We approached the question of which factors influence community structure by asking if a number of physical variables, phytoplankton abundance and recruitment of the dominant species (Mytilus edulis), may explain variation in community structure along an apparently homogeneous stretch of shoreline. Although we controlled for m-scale variation by limiting sampling to specific portions of the intertidal communities, variation at this scale accounted for almost an order of magnitude more of the total variation in the analyses than did variation at the $\mathrm{km}$-scale. Despite this large within-site variation and the a priori notion that study sites differed only slightly, if at all, significant portions of the variation in recruitment and community structure were nonetheless explained by the measured variables. Below, we consider each factor in turn and discuss how each may have influenced recruitment of $M$. edulis and/or community structure.

\section{Coastal heterogeneity}

Mesoscale coastal heterogeneity is known to influence community structure, various physical processes and recruitment. For example, entrainment of planktonic larvae within embayments has been suggested to limit the dispersal of polychaetes (Lagadeuc 1992, Thiébault et al. 1994), seastars (Sewell \& Watson 1993), barnacles (Bennell 1981, Kendall et al. 1982), and diverse assemblages of zoo- and meroplankton (Graham 1992, 1993, Wing et al. 1995, Archambault et al. 1998). Recent studies (Archambault \& Bourget 1999) have shown that such entrainment influences community structure within embayments. Studies of headlands indicated their influence on aggregations of zoo- and meroplankton (e.g., Alldredge \& Hamner 1980, Murdoch 1989, Graham 1992, Sasaki \& Shepard 1995) and some attempts have been made to correlate these patterns to benthic and intertidal community structures around them (e.g., Ebert \& Russell 1988, Rankin et al. 1994). Others studies on headlands have linked variation in community structure to differences in various physical and/or ecological processes (e.g., Menge 1978a,b). More recently, attempts have been made to link various processes and intertidal community structure to the scale of different sources of coastal heterogeneity (Archambault \& Bourget 1996, 1999, Archambault et al. 1998, 1999, Blanchard \& Bourget 1999). However, many of the above studies document unique events and it is incorrect to extrapolate from such unreplicated studies (Hurlbert 1984, Underwood \& Petraitis 1993) even though, when taken together, they may provide a more global understanding (Paine 1991).
Of all the comparisons of community structure and of the different variables measured in this study, only species richness was influenced by the scale of coastal heterogeneity examined, embayment size, such that straight coastlines supported a higher mean number of species than did embayments. Species richness in fjords declines with increasing distance from their mouths (Hansen \& Ingólfsson 1993) and Rapoport (1994) suggests that lower richness in embayments may reflect differences in extinction and recruitment. Water within embayments may become entrained and thus eventually depauperate of planktonic larvae, thereby reducing overall recruitment (Graham 1992) and presumably species richness. However, the results of our recruitment study are not consistent with this hypothesis as recruitment of Mytilus edulis was not a function of embayment size. Furthermore, other studies performed in the same general area as this study found that both the concentration of zooplankton (Archambault et al. 1998) and recruitment on settling plates (Archambault \& Bourget 1999) were generally higher within embayments (mostly larger than those examined in this study) than in zones along the linear coastlines surrounding them.

\section{Climatic severity}

Diversity (both $H^{\prime}$ no and $H^{\prime}{ }_{\text {wt }}$ ) in this study was a function of each of the measures of wave exposure calculated. The intermediate disturbance hypothesis states that species diversity is maximal at intermediate levels of disturbance as a balance is struck between the competitive exclusion of competitively inferior but more resistant species and the destruction of those competitively superior but less resistant species (Sousa 1979, Petraitis et al. 1989, Aronson \& Precht 1995, Dial \& Roughgarden 1998). The wave regime in the St. Lawrence estuary is quite tame compared to open coastal regions. For instance, the maximal wave force recorded in this study translates to a water velocity of about $5.5 \mathrm{~m} \mathrm{~s}^{-1}$, a value surpassed at all the sites studied by Bell \& Denny (1994) in California. If we assume 'intermediate' to infer exposure regimes more severe than those of the St. Lawrence estuary, then a positive correlation between wave force and diversity as observed in this study is logical.

As is true for suspension feeders in general (Ricciardi \& Bourget 1999), mussel abundance is generally positively correlated with wave exposure (Bustamante \& Branch 1996) and may be related to rates of food delivery and flushing (Leigh et al. 1987, Leonard et al. 1998) or lower predation rates (Menge 1976). Numerous studies on mussel communities have also found overall species richness and/or diversity to increase with wave 
exposure (e.g., Suchanek 1979, Tsuchiya 1979, Jacobi $1987 a, b)$. That a correlation between exposure and diversity was observed in this study, despite only slight differences in exposure between sites, emphasizes the importance of this factor in structuring intertidal communities.

Water flux had no effect on the recruitment of Mytilus edulis. This was unexpected, as an increase in water flux should concomitantly increase larval supply and therefore recruitment. Furthermore, water flux has been shown to be a good predictor of recruitment of both mussels (Hunt \& Scheibling 1995, Leonard et al. 1998) and barnacles (Yund et al. 1991, Sanford et al. 1994, Judge \& Craig 1997). The observed inter-site variation in water flux was perhaps too small to have had a measurable effect, given the other factors that influence recruitment. In contrast to water flux, both the mean and maximal wave forces were correlated with recruitment. Recruitment of mussels (Menge et al. 1994, Robles 1997, Connolly \& Roughgarden 1998) and barnacles (Caffey 1985, Sutherland 1990) has been shown to be positively correlated with exposure. However, such correlations may in fact be more related to larval supply than to exposure itself, as more sheltered sites may also lie in settlement shadows (Connolly \& Roughgarden 1998).

\section{Energy supply}

Phytoplankton abundance varied among dates but was consistently lowest in inshore zones, as has been reported in a number of other studies (Bustamante et al. 1995, Archambault et al. 1999 and references therein). As phytoplankton sampling in our study was done directly over the mussel beds studied and at the same depth further offshore, differences between the 2 zones may represent depletion of the local phytoplankton populations by mussel filtration in the inshore zone. Numerous studies (Cloern 1982, Fréchette \& Bourget 1985, Asmus \& Asmus 1991, Prins et al. 1996, Wilson-Ormond et al. 1997) have shown bivalve grazing to decrease the local concentration of phytoplankton. Similarly, Archambault et al. (1999) also suggest that grazing by zoo- and meroplankton entrained within embayments or along the coast may also contribute to the reduction of phytoplankton in inshore zones. Although it has been suggested that the byproducts of both mussels (Asmus \& Asmus 1991, Barranguet 1997) and barnacles (Williamson \& Rees 1995) may actually increase primary production locally, a rapid flushing of the sites studied would not allow these effects to be expressed (Archambault et al. 1999). A further possibility is that lower concentrations of nutrients in inshore zones (Demers et al. 1989) may result from macrophytes acting as sinks for inorganic nitrogen (Raine \& Patching 1980), thereby limiting primary production of phytoplankton and abundance close to the coast.

Recruitment of Mytilus edulis was positively correlated to chl a concentration in this study. Menge et al. $(1994,1995,1997 a$, b) have made the same observation for 2 sites on the west coast of North America. Higher concentrations of food may potentially increase survivorship or growth of newly settled larvae. However, given that phytoplankton abundance is highly variable at both temporal and spatial scales (Therriault \& Platt 1981, Smaal \& Haas 1997) and that mussel larvae may survive prolonged periods without food (see reviews in Bayne 1976, Lutz \& Kennish 1992), we are hesitant to suggest higher growth or survivorship as the cause for the statistical relationship between recruitment and phytoplankton abundance.

Phytoplankton abundance or primary production are important factors in determining community structure, particularly in communities dominated by filter feeders (Dahlhoff \& Menge 1996), such as those studied here. However, phytoplankton abundance had no significant effect on any of the indices of community structure measured in this study. We suggest that the slight variation in phytoplankton abundance we observed was insufficient to create detectable differences in community structure. Consistent significant along-shore variation in phytoplankton abundance may be only detectable at scales larger than those considered in this study.

\section{Recruitment}

That the strong recruitment gradient observed in this study was related to community structure (species richness) is not surprising. Numerous theoretical and empirical studies have shown that this may come about directly by increasing the number and/or types of organisms recruiting, or indirectly by modifying ecological processes such as predation and competition (see reviews in Underwood \& Denley 1984, Menge 1991, Booth \& Brosnan 1995, Caley et al. 1996). If recruitment influenced richness directly, this should be most evident for species with life cycles with planktonic stages. A comparison of 2 communities at opposite ends of the ranges for both recruitment and species richness (lowest richness and 2nd lowest recruitment vs highest richness and recruitment) does not support this hypothesis (data not shown). In fact, most of the species that were more prevalent at the high richness site have direct-development life cycles and therefore a higher overall recruitment of organisms from the meroplankton may not explain the observed variation in richness. 


\section{Along-shore variation}

Of all the independent variables, along-shore linear distance was the single best predictor of both recruitment and $H^{\prime}$ no. Although a number of studies have noted considerable among-site variation in the recruitment of intertidal invertebrates (e.g., Caffey 1985, Raimondi 1990, Sutherland 1990, Molares \& Fuentes 1995), the sites compared typically differed greatly in a number of other ways, each of which may have contributed to the observed variation in recruitment. We controlled for other factors and found recruitment decreased by an order of magnitude almost linearly along the ca $15 \mathrm{~km}$ of coastline studied. Spatial and temporal variations in the recruitment of the barnacle Tesseropora rosea have been suggested to result from 2 to $3 \mathrm{~km}$ long larval clouds that come into irregular contact with the shoreline at the whims of the weather (Caffey 1985). Such a process, however, would be less likely to manifest itself with a method that integrates longer-term variation in recruitment, as was employed in this study. The pattern of recruitment we observed more likely results from a more consistent oceanographic process. Variation in upwelling intensity may cause differences in recruitment (Farrell et al. 1991) and Connolly \& Roughgarden (1998) have suggested that a gradient in upwelling intensity may alter recruitment strength along the mid-Pacific coast of North America. Such a mechanism operating at a smaller spatial scale could explain the marked decline in recruitment observed in this study. Gradients in surface slicks associated with internal waves or tides (Shanks \& Wright 1987, LeFèvre \& Bourget 1992) may also account for the spatial trends observed in this study. Monitoring water temperatures along the study area may suffice to highlight these effects. Knowledge of the submarine topography of the study area could yield important clues into the mechanism of the along-shore variation in recruitment as various topographic irregularities may result in predictable patterns (Shanks \& Wright 1987). The observed pattern may also result from downstream sites lying within the recruitment shadow of upstream ones.

Few studies have considered how community structure varies over apparently homogeneous shorelines. Schoch \& Dethier (1996) compared community structure among sites with similar characteristics along $5 \mathrm{~km}$ of Washington coastline and suggested that communities from similar habitats differed little. However, their data do not support this claim and the different sites do actually differ considerably. Most other studies that compare community structure among similar sites only look at 1 or a small number of species, and in many cases the results are part of larger studies designed to examine the spatial scales at which community structure is most variable.

\section{Conclusions}

This study shows that communities from adjacent sites that experience ostensibly similar environmental stimuli do in fact differ and that these differences may be, in part, attributed to a number of easily measured variables. Although little of the total variation in community structure is explained by our models, the comparatively large intra-site variation makes the significance of these results that much more surprising. They also underscore the importance of each of the factors measured in determining community structure. Further studies covering a range of each of the factors (and more) are needed to understand the relation between these and intertidal community structure. To our knowledge, this is the first observation of an alongshore linear trend in diversity at the mesoscale. More importantly, this trend existed even after other factors were controlled for. Biological factors such as predation and competition that are known to influence diversity were not considered in this study but we assume them to have been relatively constant and low in the area studied. The only major predator is Nucella lapillus, and although it was present at all sites, it had an evenly low abundance the year in which the sampling took place (McKindsey pers. obs.). Also, the manipulative studies needed to study such ecological factors (Hairston 1989, Menge et al. 1994) are not possible given the annual abrasion by ice and the comparatively slow speed at which communities develop in the study area. However, they remain an unexplored factor.

Acknowledgements. We thank P. A. Paradis, M. Veret, and I. Corbet for their assistance in the field. M. J. Abgrall, C. A. Drouin, and N. Moreau helped in the analysis of community and recruitment samples in the lab. G. Daigle (Service de Consultation Statistique, Département de mathématiques et de statistique, Université Laval) provided statistical advice and J. Y. Anctil provided logistical support in the field. We are also grateful to P. Archambault and A. Ricciardi for comments on an earlier draft of this manuscript. This project is part of the Coastal Heterogeneity and Scaling Experiment (CHASE) and was supported by a Natural Sciences and Engineering Research Council of Canada (NSERC) grant to E.B. Funding to C.W.M. was provided through grants from the Groupe Interuniversitaire de Recherches Océanographique du Québec (GIROQ), the Fondation de l'Université Laval and the Fonds de soutien au doctorat from Université Laval.

\section{LITERATURE CITED}

Addicott JF, Aho JM, Antolin MF, Padilla DK, Richardson JS, Soluk DA (1987) Ecological neighbourhoods: scaling and environmental parameters. Oikos 49:340-346

Alldredge AL, Hamner WM (1980) Recurring aggregation of zooplankton by a tidal current. Estuar Coast Mar Sci 10: 31-37 
Archambault P, Bourget E (1996) Scales of coastal heterogeneity and benthic intertidal species richness, diversity and abundance. Mar Ecol Prog Ser 136:111-121

Archambault P, Bourget E (1999) Influence of shoreline configuration on spatial variation of meroplanktonic larvae, recruitment and diversity of benthic subtidal communities. J Exp Mar Biol Ecol 241:309-333

Archambault P, Roff JC, Bourget E, Bang B, Ingram G (1998) Nearshore abundance of zooplankton in relation to shoreline configuration and mechanisms involved. J Plankton Res 20:671-690

Archambault P, McKindsey CW, Bourget E (1999) Large-scale shoreline configuration influences phytoplankton concentration and mussel growth. Estuar Coast Shelf Sci 49: 193-208

Aronson RB, Precht WF (1995) Landscape patterns and coral reef diversity: a test of the intermediate disturbance hypothesis. J Exp Mar Biol Ecol 192:1-14

Asmus RM, Asmus H (1991) Mussel beds: limiting or promoting phytoplankton? J Exp Mar Biol Ecol 148:215-232

Bachelet G (1990) The choice of sieving mesh size in the quantitative assessment of marine macrobenthos: a necessary compromise between aims and constraints. Mar Environ Res 30:21-35

Barranguet C (1997) The role of microphotobenthic primary production in a Mediterranean mussel culture area. Estuar Coast Shelf Sci 44:753-765

Bayne BL (1976) The biology of mussel larvae. In: Bayne BL (ed) Marine mussels: their ecology and physiology. Cambridge University Press, Cambridge, p 81-120

Bell EC, Denny MW (1994) Quantifying 'wave exposure': a simple device for recording maximal velocity and results of its use at several field sites. J Exp Mar Biol Ecol 181:9-29

Bennell SJ (1981) Some observations on the littoral barnacle populations of north Wales. Mar Environ Res 5:227-240

Bergeron P, Bourget E (1986) Shore topography and spatial partitioning of crevice refuges by sessile epibenthos in an ice disturbed environment. Mar Ecol Prog Ser 28:129-145

Bingham BL (1992) Life histories in an epifaunal community: coupling of adult and larval processes. Ecology 73 : 2244-2259

Blanchard D, Bourget E (1999) Scales of coastal heterogeneity: influence on intertidal community structure. Mar Ecol Prog Ser 179:163-173

Booth DJ, Brosnan DM (1995) The role of recruitment dynamics in rocky shore and coral reef fish communities. Adv Ecol Res 26:309-385

Brosnan DM, Crumrine LL (1994) Effects of human trampling on marine rocky shore communities. J Exp Mar Biol Ecol 177:79-97

Bustamante RH, Branch GM (1996) Large scale patterns and trophic structure of southern African shores: the roles of geographic variation and wave exposure. J Biogeogr 23: 339-351

Bustamante RH, Branch GM, Eekhout S, Robertson B, Zoutendyk P, Schleyer M, Dye A, Hanekom N, Keats D, Jurd M, McQuaid C (1995) Gradients of intertidal primary productivity around the coast of South Africa and their relationships with consumer biomass. Oecologia 102:189-201

Caffey HM (1985) Spatial recruitment and temporal variation in settlement and recruitment of intertidal barnacles. Ecol Monogr 55:313-332

Caley MJ, Carr MH, Hixon MA, Hughes TP, Jones GP, Menge BA (1996) Recruitment and the local dynamics of open marine populations. Annu Rev Ecol Syst 27:477-500

Carr MR (1996) PRIMER user manual. Plymouth Marine Laboratory, Plymouth
Clarke KR (1993) Non-parametric analyses of changes in community structure. Aust J Ecol 18:117-143

Clarke KR, Ainsworth M (1993) A method of linking multivariate community structure to environmental variables. Mar Ecol Prog Ser 92:205-219

Clarke KR, Green RH (1988) Statistical design and analysis for a 'biological effects' study. Mar Ecol Prog Ser 46: 213-226

Cloern JE (1982) Does the benthos control phytoplankton biomass in south San Francisco Bay? Mar Ecol Prog Ser 9: 191-202

Connell JH (1978) Diversity in tropical rain forests and coral reefs. Science 199:1302-1310

Connolly SR, Roughgarden J (1998) A latitudinal gradient in northeast Pacific intertidal community structure: evidence for an oceanographically based synthesis of marine community theory. Am Nat 151:311-326

Cornell HV, Lawton JH (1992) Species interactions, local and regional processes, and limits to the richness of ecological communities: a theoretical perspective. J Anim Ecol 61: $1-12$

Currie DJ (1991) Energy and large-scale patterns of animaland plant-species richness. Am Nat 137:27-49

Dahlhoff EP, Menge BA (1996) Influence of phytoplankton concentration and wave exposure on the ecophysiology of Mytilus californianus. Mar Ecol Prog Ser 144:97-107

Demers S, Therriault JC, Bourget E, Désilets H (1989) Smallscale gradients of phytoplankton productivity in the littoral fringe. Mar Biol 100:393-399

Denny M (1995) Predicting physical disturbance: mechanistic approaches to the study of survivorship on wave-swept shores. Ecol Monogr 65:371-418

Denny MW, Gaines SD (1990) On the prediction of maximal intertidal wave forces. Limnol Oceanogr 35:1-15

Dial R, Roughgarden J (1998) Theory of marine communities: the intermediate disturbance hypothesis. Ecology 79: 1412-1424

Dye AH (1992) Experimental studies of succession and stability in rocky intertidal communities subject to artisanal shellfish gathering. Neth J Sea Res 30:209-217

Ebert TA, Russell MP (1988) Latitudinal variation in size structure of the west coast sea urchin: a correlation with headlands. Limnol Oceanogr 33:286-294

Farrell TM, Bracher D, Roughgarden J (1991) Cross-shelf transport causes recruitment to intertidal populations in central California. Limnol Oceanogr 36:279-288

Fradette P, Bourget E (1980) Ecology of benthic epifauna of the estuary and gulf of St. Lawrence: factors influencing their distribution and abundance on buoys. Can J Fish Aquat Sci 37:979-999

Fréchette M, Bourget E (1985) Energy flow between the pelagic and benthic zones: factors controlling particulate organic matter available to an intertidal mussel bed. Can J Fish Aquat Sci 42:1158-1165

Gaines S, Roughgarden J (1985) Larval settlement rate: a leading determinant of structure in an ecological community of the marine intertidal zone. Proc Natl Acad Sci 82: $3707-3711$

Graham WM (1992) Persistent 'upwelling shadows' and their influence of zooplankton distributions. Mar Biol 114: 561-570

Graham WM (1993) Spatio-temporal scale assessment of an 'upwelling shadow' in northern Monterey Bay, California. Estuaries 16:83-91

Hairston NG (1989) Ecological experiments: purpose, design and execution. Cambridge University Press, Cambridge

Hansen JR, Ingólfsson (1993) Patterns in species composition 
of rocky shore communities in subarctic fjords of eastern Iceland. Mar Biol 117:469-487

Hardy MA (1993) Regression with dummy variables. Sage Publications, Newbury Park, CA

Hunt HL, Scheibling RE (1995) Physical and biological factors influencing mussel (Mytilus trossulus, M. edulis) settlement on a wave-exposed rocky shore. Mar Ecol Prog Ser 135:135-145

Hurlbert SH (1984) Pseudoreplication and the design of ecological field experiments. Ecol Monogr 54:187-211

Jacobi CM (1987a) The invertebrate fauna associated with intertidal beds of the brown mussel Perna perna (L.) from Santos, Brazil. Stud Neotrop Fauna Environ 22:57-72

Jacobi CM (1987b) Spatial and temporal distribution of Amphipoda associated with mussel beds from the Bay of Santos (Brazil). Mar Ecol Prog Ser 35:51-58

Jones WE, Demetropoulos A (1968) Exposure to wave action: measurements of an important ecological parameter on rocky shores on Anglesey. J Exp Mar Biol Ecol 2:46-63

Judge ML, Craig SF (1997) Positive flow dependence in the initial colonization of a fouling community: results from in situ water current manipulations. J Exp Mar Biol Ecol 210: 209-222

Kendall MA, Bowman RS, Williamson P, Lewis JR (1982) Settlement patterns, density and stability in the barnacle Balanus balanoides. Neth J Sea Res 16:119-126

Lagadeuc Y (1992) Transport larvaire en Manche. Exemple de Pectinaria koreni (Malmgren), annélide polychaète, en baie de Seine. Oceanol Acta 15:383-395

LeFèvre J, Bourget E (1992) Hydrodynamics and behaviour: transport processes in marine invertebrate larvae. Trends Ecol Evol 7:288-289

Leigh EG, Paine RT, Quinn JF, Suchanek TH (1987) Wave energy and intertidal productivity. Proc Natl Acad Sci USA 84:1314-1318

Leonard GH, Levine JM, Schmidt PR, Bertness MD (1998) Flow-driven variation in intertidal community structure in a Maine estuary. Ecology 79:1395-1411

Lutz RA, Kennish MJ (1992) Ecology and morphology of larval and early postlarval mussels. In: Gosling E (ed) The mussel Mytilus: ecology, physiology, genetics and culture. Elsevier, Amsterdam, p 53-85

Mathieson AC, Penniman CA, Harris LG (1991) Northwest Atlantic rocky shore ecology. In: Mathieson $\mathrm{AC}$, Nienhuis (eds) Ecosystems of the world, Vol 24. Intertidal and littoral ecosystems. Elsevier, Amsterdam, p 109-191

McQuaid CD, Branch GM (1984) Influence of sea temperature, substratum and wave exposure on rocky intertidal communities: an analysis of faunal and floral biomass. Mar Ecol Prog Ser 19:145-151

Menge BA (1976) Organization of the New England rocky intertidal community: role of predation, competition, and environmental heterogeneity. Ecol Monogr 46:355-393

Menge BA (1978a) Predation intensity in a rocky intertidal community. Relation between predator foraging activity and environmental harshness. Oecologia 34:1-16

Menge BA (1978b) Predation intensity in a rocky intertidal community. Effects of an algal canopy, wave action and desiccation on predator feeding rates. Oecologia 34:17-35

Menge BA (1991) Relative importance of recruitment and other causes of variation in rocky intertidal community structure. J Exp Mar Biol Ecol 146:69-100

Menge BA, Berlow EL, Blanchette CA, Navarrete SA, Yamada SB (1994) The keystone species concept: variation in interaction strength in a rocky intertidal habitat. Ecol Monogr 64:249-286

Menge BA, Daley B, Wheeler PA (1995) Control of interaction strength in marine benthic communities. In: Polis GA Winemiller KO (eds) Food webs: integration of patterns and dynamics. Chapman and Hall, New York, p 258-274

Menge BA, Daley BA, Wheeler PA, Dahlhoff E, Sanford E, Strub PT (1997a) Benthic-pelagic links and rocky intertidal communities: bottom-up effects on top-down control? Proc Natl Acad Sci USA 94:14530-14535

Menge BA, Daley BA, Wheeler PA, Strub PT (1997b) Rocky intertidal oceanography: an association between community structure and nearshore phytoplankton concentration. Limnol Oceanogr 42:57-66

Molares J, Fuentes J (1995) Recruitment of the mussel Mytilus galloprovincialis on collectors situated on the intertidal zone in the Riá de Arousa (NW Spain). Aquaculture 138:131-137

Murdoch RC (1989) The effects of a headland eddy on surface macro-zooplankton assemblages north of Otago Peninsula, New Zealand. Estuar Coast Shelf Sci 29:361-383

Muus BJ (1968) A field method for measuring 'exposure' by means of plaster balls. Sarsia 34:61-68

Newell CR, Shumway SE, Cucci TL, Selvin R (1989) The effect of natural seston particle size and type on feeding rates, feeding selectivity and food resource availability for the mussel Mytilus edulis Linnaeus, 1758 at bottom culture sites in Maine. J Shellfish Res 8:187-196

Okubo A (1973) Effect of shoreline irregularities on streamwise dispersion in estuaries and other embayments. Neth J Sea Res 6:213-224

Osman RW (1977) The establishment and development of a marine epifaunal community. Ecol Monogr 47:37-63

Paine RT (1991) Between Scylla and Charybdis: do some kinds of criticism merit a response? Oikos 62:90-92

Petraitis PS, Latham RE, Niesenbaum RA (1989) The maintenance of species diversity by disturbance. Q Rev Biol 64: 393-418

Pianka ER (1988) Evolutionary ecology. Harper and Row, New York

Pouliot F, Bourget E, Fréchette M (1995) Optimizing the design of giant scallop (Plactopecten magellanicus) spat collectors: field experiments. Mar Biol 123:277-284

Prins TC, Smaal AC, Pouwer AJ, Dankers N (1996) Filtration and resuspension of particulate matter and phytoplankton on an intertidal mussel bed in the Oosterschelde estuary (SW Netherlands). Mar Ecol Prog Ser 142:121-134

Pugh PJA, Davenport J (1997) Colonization vs. disturbance: the effects of sustained ice-scouring on intertidal communities. J Exp Mar Biol Ecol 210:1-21

Raimondi PT (1990) Patterns, mechanisms, consequences of variability in settlement and recruitment of an intertidal barnacle. Ecol Monogr 60:283-309

Raine RCT, Patching JW (1980) Aspects of carbon and nitrogen cycling in a shallow marine environment. J Exp Mar Biol Ecol 47:127-139

Rankin KL, Mullineaux LS, Geyer WR (1994) Transport of juvenile gem clams (Gemma gemma) in a headland wake. Estuaries 17:655-667

Rapoport EH (1994) Remarks on marine and continental biogeography: an areographical viewpoint. Phil Trans R Soc Lond B 343:71-78

Reish DJ (1959) A discussion of the importance of screen size in washing quantitative marine bottom samples. Ecology 40:307-309

Ricciardi A, Bourget E (1999) Global patterns of macroinvertebrate biomass in marine intertidal communities. Mar Ecol Prog Ser 185:21-35

Rice WR (1989) Analyzing tables of statistical tests. Evolution 43:223-225

Robles CD (1997) Changing recruitment in constant species 
assemblages: implications for predation theory in intertidal communities. Ecology 78:1400-1414

Roff JC, Pett RJ, Rogers GF, Budgell WP (1979) A study of plankton ecology in Chesterfield Inlet, Northwest Territories: an arctic estuary. In: Kennedy VS (ed) Estuarine perspectives. Academic Press, New York, p 185-197

Sanford E, Bermudez D, Bertness MD, Gaines SD (1994) Flow, food supply and acorn barnacle population dynamics. Mar Ecol Prog Ser 104:49-62

Sanford LP, Boicourt WC, Rives SR (1992) Model for estimating tidal flushing of small embayments. J Waterway Port Coastal Ocean Eng 118:635-654

Sasaki R, Shepard SA (1995) Larval dispersal and recruitment of Haliotis discus hannai and Tegula spp. on Miyagi coasts, Japan. Aust J Mar Freshw Res 46:519-529

SAS Institute (1996) The SAS system for Windows. SAS Institute Inc, Cary, NC

Schluter D, Ricklefs RE (1993) Species diversity: an introduction to the problem. In: Ricklefs RE, Schluter D (eds) Species diversity in ecological communities: historical and geographic perspectives. University of Chicago Press, Chicago, p 1-10

Schoch GC, Dethier MN (1996) Scaling up: the statistical linkage between organismal abundance and geomorphology on rocky intertidal shores. J Exp Mar Biol 201:37-72

Seed R (1976) Ecology. In: Bayne BL (ed) Marine mussels: their ecology and physiology. Cambridge University Press, Cambridge, p 13-65

Seed R, Suchanek TH (1992) Population and community ecology of Mytilus. In: Gosling E (ed) The mussel Mytilus: ecology, physiology, genetics and culture. Elsevier, Amsterdam, p 87-169

Sewell MA, Watson JC (1993) A 'source' for asteroid larvae?: recruitment of Pisaster ochraceus, Pycnopodia helianthoides and Dermasterias imbricata in Nootka Sound, British Columbia. Mar Biol 117:387-398

Shanks AL, Wright WG (1987) Internal-wave-mediated shoreward transport of cyprids, megalopae, and gammarids and correlated longshore differences in settling rate of intertidal barnacles. J Exp Mar Biol Ecol 114:1-13

Smaal AC, Haas HA (1997) Seston dynamics and food availability on mussel and cockle beds. Estuar Coast Shelf Sci 45:247-259

Sokal RR, Rohlf FJ (1995) Biometry: the principles and practice of statistics in biological research. WH Freeman \& Company, San Francisco

Sousa WP (1979) Disturbance in marine intertidal boulder fields: the nonequilibrium maintenance of species diversity. Ecology 60:1225-1239

Suchanek TH (1979) The Mytilus californianus community: studies on the composition, structure, organization, and dynamics of a mussel bed. $\mathrm{PhD}$ dissertation, University of Washington, Seattle

Suchanek TH (1985) Mussels and their role in structuring

Editorial responsibility: Otto Kinne (Editor), Oldendorf/Luhe, Germany rocky shore communities. In: Moore PG, Seed R (eds) The ecology of rocky coasts. Hodder and Stroughton, London, p 70-96

Sutherland JP (1990) Recruitment regulates demographic variation in a tropical intertidal barnacle. Ecology 71: 955-972

Tabachnick BD, Fidell LS (1989) Using multivariate statistics. Harper \& Row, New York

Therriault JC, Platt T (1981) Environmental control of phytoplankton patchiness. Can J Fish Aquat Sci 38:638-641

Thiébault E, Dauvin JC, Lagadeuc Y (1994) Horizontal distribution and retention of Owenia fusiformis larvae (Annelida: Polychaeta) in the Bay of Seine. J Mar Biol Assoc UK 74:129-142

Tokeshi M (1993) Species abundance patterns and community structure. Adv Ecol Res 24:111-186

Tsuchiya M (1979) Quantitative survey of intertidal organisms on rocky shores in Mutsu Bay, with special reference to the influence to wave action. Bull Mar Biol Stn Asamushi Tohoku Univ 16:69-86

Underwood AJ (1997) Experiments in ecology: their logical design and interpretation using analysis of variance. Cambridge University Press, Cambridge

Underwood AJ, Denley EJ (1984) Paradigms, explanations, and generalizations in models for the structure of intertidal communities on rocky shores. In: Simberloff D, Strong DR (eds) Ecological communities: conceptual issues and the evidence. Princeton University Press, Princeton, p 151-180

Underwood AJ, Petraitis PS (1993) Structure of intertidal assemblages in different locations: how can local processes be compared? In: Ricklefs RE, Schluter D (eds) Species diversity in ecological communities: historical and geographic perspectives. University of Chicago Press, Chicago, p 39-51

Williamson JE, Rees TAV (1995) Nutritional interaction in an alga-barnacle association. Oecologia 99:16-20

Wilson-Ormond EA, Powell EN, Ray SM (1997) Short-term and small-scale variation in food availability to natural oyster populations: food, flow and flux. PSZN I: Mar Ecol 18:1-34

Wing SR, Largier JL, Botsford LW, Quinn JF (1995) Settlement and transport of benthic invertebrates in an intermittent upwelling region. Limnol Oceanogr 40:316-329

Wolanski E, Hamner WM (1988) Topographically controlled fronts in the ocean and their biological influence. Science 241:177-181

Wright DH, Currie DJ, Maurer BA (1993) Energy supply and patterns of species richness on local and regional scales. In: Ricklefs RE, Schluter D (eds) Species diversity in ecological communities: historical and geographic perspectives. University of Chicago Press, Chicago, p 66-76

Yund PO, Gaines SD, Bertness MD (1991) Cylindrical tube traps for larval sampling. Limnol Oceanogr 36:1167-1177

Submitted: November 5, 1999; Accepted: March 28, 2000 Proofs received from author(s): October 4, 2000 